\title{
Serum adipokines and vitamin D levels in patients with type 1 diabetes mellitus
}

Mohamed M. Ismail ${ }^{1}$, Tamer A. Abdel Hamid ${ }^{1}$, Alshaymaa A. Ibrahim², Huda Marzouk ${ }^{1}$

${ }^{1}$ Pediatric Department, Faculty of Medicine, Cairo University, Cairo, Egypt ${ }^{2}$ Clinical and Chemical Pathology Department, National Research Centre, Cairo, Egypt

Submitted: 16 June 2015

Accepted: 20 September 2015

Arch Med Sci 2017; 13, 4: 738-744

DOI: https://doi.org/10.5114/aoms.2016.60680

Copyright $\odot 2016$ Termedia \& Banach

\author{
Corresponding author: \\ Alshaymaa Ahmed Ibrahim \\ National Research Centre \\ El Buhouth St, Dokki \\ Cairo, Egypt 12311 \\ Phone: +201006193988 \\ Fax +20233370931 \\ E-mail: shaymaa t@ \\ hotmail.com
}

\begin{abstract}
Introduction: Adiponectin, leptin and resistin are adipokines that play important roles in the regulation of lipid and carbohydrate metabolism in type 2 diabetes (T2DM). However, their influence in type 1 diabetes mellitus is still unknown. The aim of this study was to measure serum adiponectin, leptin and resistin levels and to investigate their relationships with vitamin $D$ and other clinical and laboratory parameters in patients with type 1 diabetes.

Material and methods: Fifty subjects with type 1 diabetes and 50 healthy age- and sex-matched subjects were selected from the Endocrinology Outpatient Clinic of Cairo University Pediatrics Hospital. Enzyme-linked immunosorbent assay was used to measure the levels of leptin, adiponectin and resistin. Vitamin D levels were measured using electro-chemiluminescence immunoassay.

Results: There were no significant differences in adiponectin and leptin levels between diabetic and control subjects ( $p=0.6$ and $p=0.5$ respectively). Resistin levels were significantly higher in the diabetic group compared to controls $(p<0.001)$ and in postpubertal patients compared to prepubertal patients $(p<0.04)$. Serum resistin in type 1 diabetes showed a negative correlation with vitamin $\mathrm{D}(p<0.001)$ and a positive correlation with glycated hemoglobin $\left(\mathrm{HbA}_{1 c}\right)(p=0.006)$, while other adipokines were not interrelated. Conclusions: These results strongly support a role of resistin and vitamin D deficiency in the pathophysiology of type 1 diabetes. Vitamin D may be involved in resistin regulation through an unknown mechanism. Further studies are recommended to understand resistin regulation in type 1 diabetes.
\end{abstract}

Key words: vitamin D, type 1 diabetes mellitus, adiponectin, leptin, resistin.

\section{Introduction}

Type 1 diabetes mellitus (T1DM) is a highly prevalent chronic disease that usually develops during infancy and adolescence. It is a geneticbased autoimmune condition resulting from absolute insulin deficiency due to immune-mediated destruction of pancreatic $\beta$ cells [1].

A relationship between T1DM and vitamin D deficiency was previously reported, and there is growing evidence that a decreased vitamin D level in pregnancy or early childhood may be associated with an increased risk of T1DM. However, this evidence is not yet conclusive [2]. Although some studies found no association between serum vitamin D levels and parameters of insulin action [3], others have shown positive associations [4]. However, it is speculated that vitamin D plays a role in glycemic control and insulin sensitivity improvement in patients with 
T1DM, and this role of vitamin D in T1DM pathogenesis may be due to its immunomodulatory actions of reducing lymphocyte proliferation and cytokine production [5].

Adipokines such as adiponectin, leptin and resistin are bioactive mediators secreted by adipose tissue [6]. They have a significant role in the regulation of lipid and carbohydrate metabolism and involvement in the inflammatory responses [7]. In contrast to type 2 diabetes, involvement of adipose tissue in the low-grade systemic inflammation observed in T1DM has been investigated far less. Indeed, alterations in circulating levels of adipokines in T1DM indicate adipose tissue involvement in T1DM pathogenesis [8].

The aim of this study was to measure serum adiponectin, leptin, and resistin levels and to investigate their relationships with vitamin $D$ and other clinical and laboratory parameters in patients with T1DM.

\section{Material and methods}

Fifty children and adolescents with T1DM (24 boys and 26 girls, mean age $12.3 \pm 1.3$ years) and 50 healthy subjects ( 28 boys and 22 girls, mean age $12.0 \pm 1.4$ years) participated in the study. All patients with T1DM were being followed in the Pediatric Endocrinology Outpatient Clinic of Cairo University Pediatric Hospital. All patients were on insulin therapy with an average dose of $1.3 \pm 0.2$ units/kg/day. Patients were selected every other day as well as the controls. Both patients and controls were matched for age and sex.

Patients with hyperlipidemia, hypertension, anemia and ongoing infection were excluded from the study. In addition, patients receiving multiple vitamin compound therapy containing vitamin $D$ during the previous year were excluded. Eligibility criteria for the control group were: 1) prepubertal and pubertal age; 2) absence of inflammatory and autoimmune diseases (acute or chronic); 3) absence of anemia, T1DM, type 2 diabetes mellitus (T2DM), and primary hyperlipidemia; and 4) not currently on regular medications including vitamin D, antihypertensive or lipid-lowering drugs. The study was approved by the ethics committee of the hospital. Written consent from parents of included subjects was taken according to the ethics committee of the hospital.

Anthropometric data included body weight and height, from which the body mass index (BMI) and body mass index $z$ score were calculated. Height was measured in centimeters using a wall-mounted stadiometer. Weight was measured in kilograms using an electronic scale. Body mass index was calculated using the formula:

$$
\mathrm{BMI}=\frac{\text { weight }[\mathrm{kg}]}{\text { height }\left[\mathrm{m}^{2}\right]} \text {. }
$$

Tanner staging is the most commonly used procedure to assess physical puberty stage. For each member a combined Tanner stage score (ranging from 3 to 13) was assigned based on the sum of stages of pubic hair (5 stages), axillary hair (3 stages) and breast development (5 stages) in females and testicular size in males (5 stages).

Following an overnight fast, blood samples were collected from subjects and patients. After separation, serum samples were immediately analyzed for adipokines. Total cholesterol, low-density lipoprotein ( $\mathrm{LDL})$, high-density lipoprotein (HDL), triglyceride and hemoglobin levels were measured by the chemical immunoassay method in both patients and controls. Glycated hemoglobin $\left(\mathrm{HbA}_{1 \mathrm{c}}\right)$ was measured as a marker of glycemic control in the diabetic patients, using enzyme-linked immunosorbent assay (ELISA). Adiponectin was measured with an ELISA (7) kit supplied by Life Technologies Corporation, Invitrogen, USA; catalog number: KHP0041. Leptin was determined using an ELISA (7) kit supplied by Life Technologies Corporation, Invitrogen, USA; catalog number: KAC228. Resistin was measured with an ELISA (7) kit supplied by Life Technologies Corporation, Invitrogen, USA; catalog number: KHP0051.

Vitamin D total assay was performed using the electro-chemiluminescence immunoassay (ECLIA) method (ELECSYS Vitamin D total assay, COBAS, Roche Diagnostics International Ltd. CH-6343 Rotkreuz, Switzerland). Most experts define vitamin D deficiency as less than $20 \mathrm{ng} / \mathrm{ml}$, while $20-30 \mathrm{ng} / \mathrm{ml}$ is considered insufficient. The preferred level for vitamin $\mathrm{D}(25-\mathrm{OH})$ is $\geq 30 \mathrm{ng} / \mathrm{ml}$ [9].

\section{Statistical analysis}

Analysis was performed using SPSS version 17 software for Windows. Data are reported as means \pm standard deviation (SD) or number (percentage). The differences between the two groups were tested by the $t$-test for independent samples with normal data distribution or by the Mann-Whitney non-parametric test. Pearson's and Spearman's correlation tests ( $r=$ correlation coefficient) were used for correlating normal and non-parametric variables, respectively. A $p$-value of $<0.05$ was considered statistically significant.

\section{Results}

Clinical characteristics, laboratory characteristics and family history of the diabetic and control subjects are shown in Table I. There were no statistically significant differences in age, sex or family history of diabetes between the patient and control group. Body mass index z score and pubertal staging did not differ significantly between cases and controls (Table I). 
Table I. Clinical and laboratory characteristics of diabetic and control subjects

\begin{tabular}{|lccc|}
\hline Parameter & $\begin{array}{c}\text { Cases } \\
(n=50)\end{array}$ & $\begin{array}{c}\text { Controls } \\
(n=50)\end{array}$ & $P$-value \\
\hline Age [years] & $12.3 \pm 1.3$ & $12.0 \pm 1.4$ & 0.2 \\
\hline Gender (M/F) & $24 / 26$ & $28 / 22$ & 0.6 \\
\hline Diabetic duration [years] & $4 \pm 1$ & - & 0.9 \\
\hline Family history of T1DM & $1(2 \%)$ & 0 & 0.9 \\
\hline Family history of T2DM & $7(14 \%)$ & $6(12 \%)$ & 0.6 \\
\hline \begin{tabular}{l} 
Combined Tanner stages: \\
\hline Prepubertal stage
\end{tabular} & $17(34 \%)$ & $20(40 \%)$ & 0.7 \\
\hline Started puberty & $33(66 \%)$ & $30(60 \%)$ & 0.2 \\
\hline BMl [kg/m²] & $17.8 \pm 4$ & $18.6 \pm 3.6$ & 0.2 \\
\hline Total cholesterol [mg/dl] & $139.6 \pm 30$ & $133.3 \pm 23.9$ & 0.1 \\
\hline Hemoglobin [g/dl] & $13.7 \pm 1.2$ & $13.1 \pm 1.1$ & $<0.0001$ \\
\hline HbA ${ }_{1 c}(\%)$ & $8.8 \pm 1.9$ & $4.9 \pm 0.4$ & - \\
\hline
\end{tabular}

Table II. Adipokines and vitamin D in diabetic and control subjects

\begin{tabular}{|lccc|}
\hline Parameter & $\begin{array}{c}\text { Cases } \\
n=50\end{array}$ & $\begin{array}{c}\text { Controls } \\
n=50\end{array}$ & $P$-value \\
\hline $\begin{array}{l}\text { Adiponectin } \\
{[\mu \mathrm{g} / \mathrm{ml}]}\end{array}$ & $9.9 \pm 4.6$ & $10.1 \pm 2.5$ & 0.6 \\
\hline Leptin $[\mathrm{ng} / \mathrm{dl}]$ & $2.8 \pm 0.8$ & $2.7 \pm 0.8$ & 0.5 \\
\hline Resistin $[\mathrm{ng} / \mathrm{dl}]$ & $4.9 \pm 1.4$ & $3.8 \pm 1.2$ & $<0.0001$ \\
\hline $\begin{array}{l}\text { 25-OH } \\
\text { Cholecalciferol } \\
\text { (vitamin D) }\end{array}$ & $17.7 \pm 8.3$ & $38.3 \pm 13.6$ & $<0.0001$ \\
\hline
\end{tabular}

There were no significant differences in adiponectin or leptin levels between diabetic and control subjects. Resistin levels were significantly higher in the diabetic group compared to controls (Table II).

Analysis investigating the correlation of adipokine levels with age, BMI, duration of diabetes,

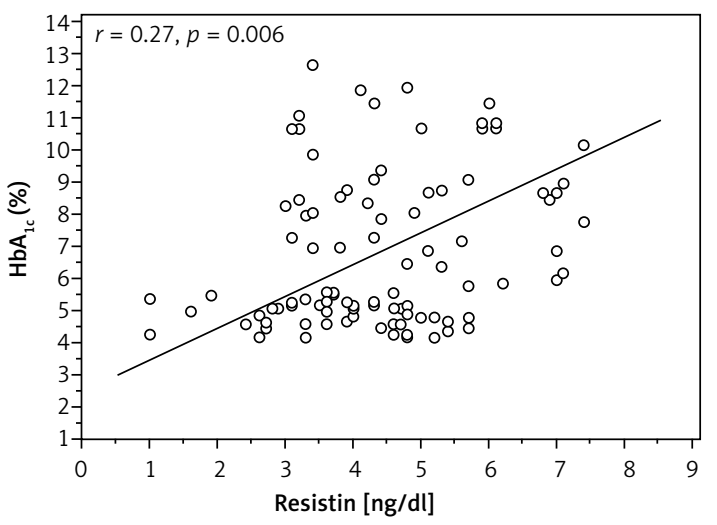

Figure 1. Correlation between glycated hemoglobin and resistin levels in type 1 diabetes mellitus subjects daily dose of insulin and $\mathrm{HbA}_{1 c}$ exhibited a positive correlation between $\mathrm{HbA}_{1 \mathrm{c}}$ and resistin levels $(r=0.27, p=0.006)$ (Figure 1). Other adipokines were not interrelated.

Regarding the changes in the adipokine levels with puberty in the diabetic group, the pre-pubertal patients showed lower levels of resistin $(4.85 \pm 1.38 \mathrm{ng} / \mathrm{dl})$, compared to the post-pubertal patients $(5.76 \pm 1.56 \mathrm{ng} / \mathrm{dl}, p=0.04)$. However, adiponectin and leptin levels showed no statistically significant difference between the two groups.

Vitamin D levels differed significantly between diabetic and control subjects. Vitamin D was deficient in $42 \%$ of patients, insufficient in $38 \%$ of patients and sufficient in $20 \%$ only, while in the control group it was deficient in $36 \%$, insufficient in $24 \%$ and sufficient in $40 \%$. Analysis investigating the correlation of vitamin D levels with age, $B M I$, duration of diabetes, daily dose of insulin and $\mathrm{HbA}_{1 \mathrm{c}}$ exhibited a negative (inverse) correlation between both $\mathrm{HbA}_{1 \mathrm{c}}$ and resistin $(r=-0.95$; $p<0.001 ; r=-0.86 ; p<0.001$, respectively) (Figures 2, 3).

\section{Discussion}

The incidence of T1DM increases by about 3-5\% every year globally [10]. Systemic cytokines and adipokines, which play a role in the autoimmune process leading to destruction of $\beta$ cells, could be potential biomarkers for different patterns of disease progression [11, 12].

Adiponectin is shown to have insulin-sensitizing and anti-inflammatory properties, and it can stimulate the pancreas to secrete insulin [13]. Previous studies reported higher adiponectin lev- 


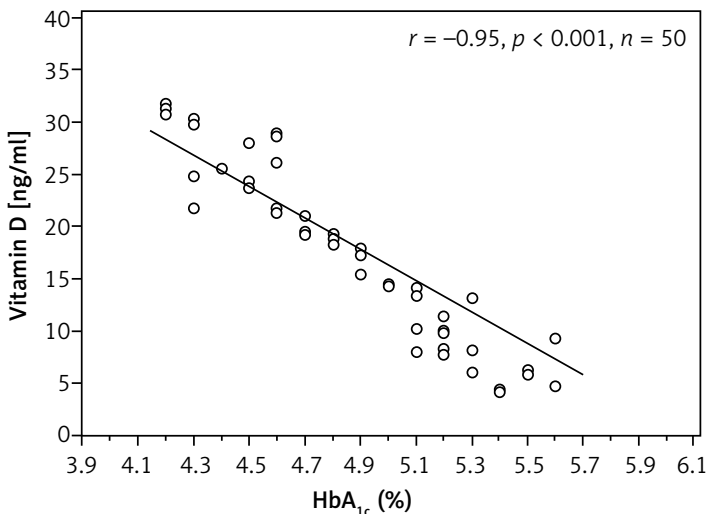

Figure 2. Correlation between glycated hemoglobin and vitamin $D$ in type 1 diabetes mellitus subjects

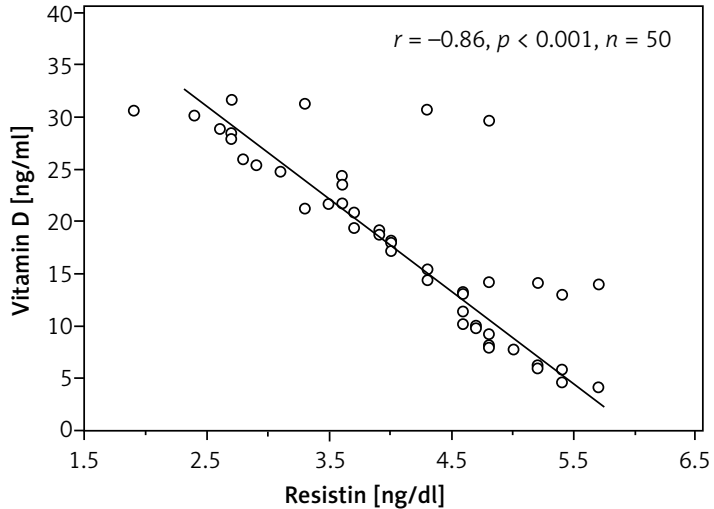

Figure 3. Correlation between resistin and vitamin $D$ in type 1 diabetes subjects els in children and adolescents with T1DM than in normal controls [14-16]. Different studies also support its role in insulin resistance $[14,16]$. In this study, serum adiponectin levels in children and adolescents with T1DM were comparable to those in the control group, and no correlation was detected between adiponectin level and diabetes duration or $\mathrm{HbA}_{1 c}$. Geyiki et al. reported comparable results [17]. Morales et al. reported no significant difference between adiponectin levels in serum of T1DM patients and a healthy control group, although they reported a significant decrease in adiponectin level in T2DM subjects compared to healthy subjects [18]. Galler et al. reported an increased level of adiponectin in children with T1DM, although they did not find any correlation between adiponectin and $\mathrm{HbA}_{1 c}$ or diabetes duration [15], but this might be attributed to differences in genetic factors and the ethnic background of the German population, which differs from the Egyptian population of our study.

However, differences in polymorphisms in the adiponectin gene, ethnic background, degree of glycemic control and physical activity have been shown to affect adiponectin levels and may explain this inconsistency between different studies [19].

Leptin is known as a key appetite-regulating hormone. Recent studies revealed that leptin has the effect of normalizing hyperglycemia and increasing insulin sensitivity [17]. The leptin data of patients with T1DM compared with healthy controls are controversial, especially during pubertal development [20]. We observed no increase in leptin levels in T1DM compared with healthy subjects, and we also found no association between leptin level and diabetes duration or $\mathrm{HbA}_{1 c}$ level. These results do not support the role of leptin in insulin resistance. The same findings were reported by Geyikli et al. [17]. Kratzsch et al. reported no increase in serum leptin in T1DM subjects during pubertal development, although they also reported a significant increase in soluble leptin recep- tor compared to healthy subjects [20]. In a study by Morales et al., a significant increase in serum leptin was reported in T2DM but no significant increase in T1DM compared to healthy subjects. Soliman et al. reported increased levels of leptin in T1DM compared with healthy subjects and reported a significant correlation between leptin levels and insulin resistance [21]. However, serum levels of leptin are markedly affected by anthropometric measures and metabolic changes during pubertal development of children and adolescents with T1DM [20].

Resistin is one of the adipokines that is thought to be involved in the inflammatory process [22]. Its biological function in humans has not been fully identified yet, and the impact of T1DM on resistin secretion remains unclear [22]. In the current study, resistin was significantly higher in diabetic subjects than in control subjects. Other studies have reported comparable results [17, 23]. Shalev et al. studied the plasma resistin levels in healthy people and patients with T1DM before and after islet transplantation. Interestingly, resistin levels were significantly higher in patients with T1DM before transplantation compared with healthy controls, but decreased to normal levels after transplantation [24]. Schäffler et al., in a large study of 555 adult patients with T2DM, 114 patients with T1DM, and 216 healthy control subjects, reported significantly higher resistin levels in control subjects than in patients with T1DM and T2DM [25]. The difference in the study by Schäffler et al. was that all groups of patient were composed of adults rather than adolescents. Furthermore, Celi et al. observed lower resistin levels in children with T1DM compared with a healthy control group [14]. Majewska et al. explained the findings of two previous studies [14, 25] by presence of hyperinsulinemia, which frequently appears in patients with T1DM and may also exert an inhibitory effect on the secretion of resistin [22]. On the other hand, Fehman et al., comparing 
resistin levels in patients with T1DM and healthy subjects, found similar levels in all subjects [26]. In an interesting study, Martos-Moreno et al. evaluated resistin concentrations in 75 children in the early stages of T1DM before starting insulin therapy and after 1 and 4 months of treatment. Their results showed no difference at any time points, and the concentrations were similar to resistin concentrations obtained from 20 healthy subjects that served as a control group [27]. However, serum resistin in children with T1DM is related to the genetic differences, disease duration, maturity of adipocytes and the dose of exogenous insulin therapy [22]. This may explain the heterogeneity of resistin levels among different studies.

This may also explain why the data reported in the literature about resistin levels are controversial, both in their relation with insulin resistance and with the progression of puberty [28-32]. However, in the present study, the pre-pubertal patients showed lower levels of resistin compared to the pubertal patients. On the other hand, Reinehr et al. reported that resistin levels did not significantly differ between prepubertal and pubertal obese subjects [28]. Again the study was performed on non-diabetic subjects [28]. In a study by Li et al., an inverse relationship was found between resistin levels and age in healthy non-diabetic subjects [29]. They explained this finding by their large sample size that allowed them to find this inverse correlation that most other studies did not find.

In this study, we also found a positive correlation between resistin and $\mathrm{HbA}_{1 \mathrm{c}}$, suggesting its role in glucose regulation and insulin resistance. These results are in accordance with Silha et al., who observed a significant correlation between resistin plasma levels and insulin resistance [30], but are in conflict with those of others suggesting that resistin does not play an important role in the development of insulin resistance in humans [31, 32].

There are a number of reports demonstrating the association between vitamin $D$ levels and onset of T1DM [33, 34], although some studies do not confirm these results [35]. In the current study, we found a significant difference between the levels of vitamin $D$ in patients compared to control subjects. Vitamin D was deficient in $42 \%$ of patients, insufficient in $38 \%$ of patients and sufficient in $20 \%$ only, while in the control group it was deficient in $36 \%$, insufficient in $24 \%$ and sufficient in $40 \%$. However, many studies have reported increased prevalence of vitamin $D$ deficiency in Middle East and Africa more than in America and Europe. Thus, the prevalence of vitamin $D$ deficiency was $43 \%$ in an Australian study [36], 60.5\% in a Swiss study [37], 25\% in an Italian study [33], and $15 \%$ in a North American study
[38], but it was reported that black American children and adolescents have a higher risk for low vitamin D status, as demonstrated in a recent pediatric study performed in the United States [39]. In a large study investigating vitamin D levels in German children and adolescents, higher prevalence of vitamin D deficiency was found among immigrants from Turkey, Arab-Islamic countries, Asia, or Africa [40]. In Qatari children, it was revealed that vitamin $D$ deficiency was higher in children with T1DM (90.6\%) compared with non-diabetic children (85.3\%) [41]. A study in Saudi Arabia demonstrated that $100 \%$ of the T1DM adults and $78 \%$ of the healthy children were vitamin $D$ deficient [42]. These variations might be explained by differences in dietary intake, sun avoidance behaviors, geographical environment, skin color, or genetic predisposition [42]. Although these studies have suggested vitamin D deficiency as a risk factor of disturbed glucose homeostasis in humans, it is still controversial, particularly in children. It remains unclear whether vitamin D deficiency in children is associated with insulin resistance [5, 33, 34]. However, the inverse correlation between vitamin $\mathrm{D}$ status and $\mathrm{HbA}_{1 c}$ concentrations that was found in this study supports the hypothesis that vitamin $\mathrm{D}$ deficiency is associated with poorer glycemic control, which can be caused by insulin resistance. Notably, other studies reported no association between vitamin $\mathrm{D}$ levels and insulin resistance in childhood obesity, but this may be due to higher vitamin $D$ levels in the patient groups, or dominant effects of adiposity parameters [43, 44].

It is thought that vitamin D plays its role in the pathogenesis of T1DM by its immunomodulatory actions of reducing lymphocyte proliferation and cytokine production [45]. To the best of our knowledge, there are no human studies that have examined the association between vitamin D and adipokines in patients with T1DM in Egypt. In this study, the analysis investigating the correlation of adipokine levels and vitamin $D$ revealed a negative correlation between vitamin $D$ and resistin levels, but other adipokines were not interrelated. In contrast, Vilarrasa et al. reported no correlation between vitamin $\mathrm{D}$ and all studied adipokines in adults with morbid obesity, although they reported an inverse relationship between vitamin D and leptin in healthy subjects [46]. Another study found that vitamin $D$ showed a positive association with adiponectin concentrations and a negative correlation with leptin and resistin in obese children [47]. However, other studies reported a positive correlation between vitamin D and adiponectin [48, 49]. Vaidya et al. mentioned that a positive relation between vitamin $\mathrm{D}$ and resistin has never been reported before, and their study was the first one to find a positive correlation between vitamin $D$ and 
resistin in Caucasian subjects with hypertension [50]. The disparity between these studies and our study could be explained by the differences between the studied groups of subjects including the disease characteristics and the age of the subjects.

However, the inconsistencies between all these different studies may again be underscored by the fact that adipokine levels are affected by genetic factors, degree of tissue adiposity, maturity of adipocytes, age at diagnosis and severity of associated pathological conditions [19, 20, 22].

The most important limitation of this study is that it is cross-sectional and thus cannot prove causality or directionality of associations.

In conclusion, we observed an increase in resistin levels that positively correlated with $\mathrm{HbA}_{1 \mathrm{c}}$ and inversely correlated with vitamin $D$ levels in patients with T1DM. These results strongly support a role of resistin and vitamin $D$ deficiency in the pathophysiology of T1DM. Vitamin D may be involved in resistin regulation through an unknown mechanism. Further studies with larger numbers of participants are needed to thoroughly investigate the relationship between vitamin $\mathrm{D}$ and adipokines in T1DM.

\section{Conflict of interest}

The authors declare no conflict of interest.

\section{References}

1. Costa LM, Vieira SE. Quality of life of adolescents with type 1 diabetes. Clinics 2015; 70: 173-9.

2. Mohammadian S, Fatahi N, Zaeri H, Vakili MA. Effect of vitamin D3 supplement in glycemic control of pediatrics with type 1 diabetes mellitus and vitamin D deficiency. J Clin Diagn Res 2015; 9: SC05-7.

3. Gulseth HL, Gjelstad IM, Tierney AC, et al. Serum vitamin $D$ concentration does not predict insulin action or secretion in European subjects with the metabolic syndrome. Diabetes Care 2010; 33: 923-5.

4. Griz LH, Bandeira F, Gabbay MA, Dib SA, Carvalho EF. Vitamin D and diabetes mellitus: an update 2013. Arq Bras Endocrinol Metabol 2014; 58: 1-8.

5. Roth CL, Elfers C, Kratz M, Hoofnagle AN. Vitamin D deficiency in obese children and its relationship to insulin resistance and adipokines. J Obes 2011; 2011: 495101.

6. Harinarayan CV. Vitamin D and diabetes mellitus. Hormones (Athens) 2014; 13: 163-81.

7. Geyikli I, Keskin M, Kör Y, Akan M. Increased resistin serum concentrations in patients with type 1 diabetes mellitus. J Clin Res Pediatr Endocrinol 2013; 5: 189-93.

8. Huerta MG. Adiponectin and leptin: potential tools in the differential diagnosis of pediatric diabetes? Rev Endocr Metab Disord 2006; 7: 187-96.

9. Holick MF. Vitamin D status: measurement, interpretation, and clinical application. Ann Epidemiol 2009; 19: 73-8.

10. Harjutsalo V, Sjöberg L, Tuomilehto J. Time trends in the incidence of type 1 diabetes in Finnish children: a cohort study. Lancet 2008; 371: 1777-82.

11. Savage DB, Sewter CP, Klenk ES, et al. Resistin expression in relation to obesity and peroxisome prolifera- tor-activated receptor-gamma action in humans. Diabetes 2001; 50: 2199-202.

12. Nagaev I, Bokarewa M, Tarkowski A, Smith U. Human resistin is a systemic immune-derived proinflammatory cytokine targeting both leukocytes and adipocytes. PLoS One 2006; 1: 31.

13. Gökşen D, Levent E, Kar S, Özen S, Darcan S. Serum adiponectin and hsCRP levels and non-invasive radiological methods in the early diagnosis of cardiovascular system complications in children and adolescents with type 1 diabetes mellitus. J Clin Res Pediatr Endocrinol 2013; 5: 174-81.

14. Celi F, Bini V, Papi F, et al. Circulating adipocytokines in non-diabetic and type 1 diabetic children: relationship to insulin therapy, glycaemic control and pubertal development. Diabet Med 2006; 23: 660-5.

15. Galler A, Gelbrich G, Kratzsch J, Noack N, Kapellen T, Kiess W. Elevated serum levels of adiponectin in children, adolescents and young adults with type 1 diabetes and the impact of age, gender, body mass index and metabolic control: a longitudinal patient. Eur J Endocrinol 2007; 157: 481-9.

16. Barnes MM, Curran-Everett D, Hamman RF, et al. Determinants of adiponectin levels in young people with type 1 diabetes. Diabet Med 2008; 25: 365-9.

17. Geyikli I, Keskin M, Yılmaz K, Akan M. Increased resistin serum concentrations in patients with type 1 diabetes mellitus. J Clin Res Pediatr Endocrinol 2013; 5: 189-93.

18. Morales A, Wasserfall C, Brusko T, et al. Adiponectin and leptin concentrations may aid in discriminating disease forms in children and adolescents with type 1 and type 2 diabetes. Diabetes Care 2004; 27: 2010-4.

19. Kaklamani V, Sadim M, Hsi A, et al. Variants of the adiponectin and adiponectin receptor 1 genes and breast cancer risk. Cancer Res 2008; 68: 3178-84.

20. Kratzsch J, Deimel A, Galler A, Kapellen T, Klinghammer A, Kiess W. Increased serum soluble leptin receptor levels in children and adolescents with type 1 diabetes mellitus. Eur J Endocrinol 2004; 151: 475-81.

21. Soliman AT, Omar M, Assem HM, et al. Serum leptin concentrations in children with type 1 diabetes mellitus: relationship to body mass index, insulin dose, and glycemic control. Metabolism 2002; 51: 292-6.

22. Majewska K, Majewski D, Skowrońska B, Fichn P. Serum resistin concentrations in children with type 1 diabetes mellitus: negative relation to body fat mass. Endokrynol Pol 2014; 65: 342-7.

23. Yazıcı D, Yavuz D, Öğünç AV, et al. Serum adipokine levels in type 1 diabetic patients: association with carotid intima media thickness. Metab Syndr Relat Disord 2012; 10: 26-31.

24. Shalev A, Patterson NB, Hirshberg B, Rother KI, Harlan DM. Resistin serum levels in type 1 diabetes pre- and post-islet transplantation. Metabolism 2004; 53: 403-4.

25. Schäffler A, Büchler C, Müller-Ladner U, et al. Identification of variables influencing resistin serum levels in patients with type 1 and type 2 diabetes mellitus. Horm Metab Res 2004; 36: 702-7.

26. Fehmann HC, Heyn J. Plasma resistin levels in patients with type 1 and type 2 diabetes mellitus and in healthy controls. Horm Metab Res 2002; 34: 671-3.

27. Martos-Moreno GA, Barrios V, Soriano-Guillén L, Argente J. Relationship between adiponectin levels, acylated ghrelin levels, and short-term body mass index changes in children with diabetes mellitus type 1 at diagnosis and after insulin therapy. Eur J Endocrinol 2006; 155: 757-61. 
28. Reinehr T, Roth CL, Menke T, Andler W. Resistin concentrations before and after weight loss in obese children. Int J Obes 2006; 30: 297-301.

29. Li M, Fisette A, Zhao XY, Deng JY, Mi J, Cianflone K. Serum resistin correlates with central obesity but weakly with insulin resistance in Chinese children and adolescents. Int J Obes 2009; 33: 424-39.

30. Silha JV, Krsek M, Skrha JV, Sucharda P, Nyomba BL, Murphy LJ. Plasma resistin, adiponectin and leptin levels in lean and obese subjects: correlations with insulin resistance. Eur J Endocrinol 2003; 149: 331-5.

31. Stepien M, Rosniak-Bak K, Paradowski M, et al. Waist circumference, ghrelin and selected adipose tissuederived adipokines as predictors of insulin resistance in obese patients: preliminary results. Med Sci Monit 2011; 17: 13-8.

32. Stepien M, Stepien A, Wlazel RN, et al. Predictors of insulin resistance in patients with obesity: a pilot study Angiology 2014; 65: 22-30.

33. Pozzilli P, Manfrini S, Crinò A, et al. Low levels of 25-hydroxyvitamin D3 and 1,25-dihydroxyvitamin D3 in patients with newly diagnosed type 1 diabetes. Horm Metab Res 2005; 37: 680-3.

34. Baumgartl HJ, Standl E, Schmidt-Gayk H, Kolb HJ, Janka HU, Ziegler AG. Changes of vitamin D3 serum concentrations at the onset of immune mediated type 1 (insulin-dependent) diabetes mellitus. Diabetes Res 1991; 16: 145-8.

35. Bierschenk L, Alexander J, Wasserfall C, Haller M, Schatz D, Atkinson M. Vitamin D levels in subjects with and without type 1 diabetes residing in a solar rich environment. Diabetes Care 2009; 32: 1977-9.

36. Greer R, Rogers $M$, Bowling F, Buntain $H$, Harris $M$, Leong $\mathrm{G}$. Australian children and adolescents with type 1 diabetes have low vitamin D levels. Med J Aust 2007; 187: 59-60.

37. Janner M, Ballinari P, Mullis PE, Fluck CE. High prevalence of vitamin D deficiency in children and adolescents with type 1 diabetes. Swiss Med Wkly 2010; 140: w13091.

38. Svoren BM, Volkening LK, Wood JR, Laffel LM. Significant vitamin $D$ deficiency in youth with type 1 diabetes mellitus. J Pediatr 2009; 154: 132-4

39. Rajakumar K, de Las Heras J, Chen TC, Lee S, Holick MF, Arslanian SA. Vitamin D status, adiposity, and lipids in black American and Caucasian children. J Clin Endocrinol Metabolism 2011; 96: 1560-7.

40. Hintzpeter B, Scheidt-Nave C, Müller MJ, Schenk L, Mensink GBM. Higher prevalence of vitamin D deficiency is associated with immigrant background among children and adolescents in Germany. J Nutrition 2008; 138: 1482-90.

41. Bener A, Alsaied A, Al-Ali M, et al. High prevalence of vitamin $D$ deficiency in type 1 diabetes mellitus and healthy children. Acta Diabetol 2009; 46: 183-9.

42. Al-Daghri NM, Al-Attas OS, Alokail MS, et al. Lower vitamin D status is more common among Saudi adults with diabetes mellitus type 1 than in non-diabetics. BMC Public Health 2014; 14: 153.

43. Lamendola CA, Ariel D, Feldman D, Reaven GM. Relations between obesity, insulin resistance, and 25-hydroxyvitamin D. Am J Clin Nutrition 2012; 95: 1055-9.

44. Heras J, Rajakumar K, Lee S, Bacha F, Holick MF, Arslanian SA. 25-Hydroxyvitamin D in obese youth across the spectrum of glucose tolerance from normal to prediabetes to type 2 diabetes. Diabetes Care 2013; 36: 2048-53.

45. Mathieu C, Adorini L. The coming of age of 1, 25-dihydroxyvitamin D3 analogs as immunomodulatory agents. Trends Mol Med 2002; 8: 174-9.
46. Vilarrasa N, Vendrell J, Maravall J, et al. Is plasma 25(OH) D related to adipokines, inflammatory cytokines and insulin resistance in both a healthy and morbidly obese population? Endocrine 2010; 38: 235-42.

47. Stokić E, Kupusinac A, Tomic-Naglic D, et al. Vitamin D and dysfunctional adipose tissue in obesity. Angiology 2015; 66: 613-8.

48. Nunlee-Bland G, Gambhir K, Abrams C, Abdul M, Vahedi $\mathrm{M}$, Odonkor W. Vitamin D deficiency and insulin resistance in obese African-American adolescents. J Pediatr Endocrinol Metabolism 2011; 24: 29-33.

49. Vaidya A, Forman JP, Underwood PC, et al. The influence of body mass index and renin-angiotensin-aldosterone system activity on the relationship between 25-hydroxyvitamin D and adiponectin in Caucasian men. Eur J Endocrinol 2011; 164: 995-1002.

50. Vaidya A, Pojoga L, Underwood PC, et al. The association of plasma resistin with dietary sodium manipulation, the renin-angiotensin-aldosterone system and 25-hydroxyvitamin D(3) in human hypertension. Clin Endocrinol 2011; 74: 294-9. 